\title{
ALAT EKSTRAKTOR-EVAPORATOR ZAT WARNA ALAMI DARI BUAH MANGROVE, MAHONI DAN KULIT TINGI UNTUK PEWARNA BATIK RAMAH LINGKUNGAN
}

\author{
Paryanto $^{1)}$, Adrian Nur ${ }^{1)}$ dan Desy Nurcahyanti' \\ ${ }^{1}$ Program Studi Teknik Kimia, Fakultas Teknik \\ ${ }^{2)}$ Program Studi Kriya Seni/Tekstil FSRD \\ Universitas Sebelas Maret \\ Jl. Ir Sutami No. 36A Surakarta \\ Telp./Fax. +62271 632112 \\ Email : paryanto.uns@gmail.com
}

\begin{abstract}
Abstrak
Penggunaan zat warna alami sekarang sudah mulai ditinggalkan karena adanya zat warna sintetis yang praktis dalam penggunaanya, serta mempunyai warna yang mencolok dan lebih seragam, mudah diaplikasikan. Dalam penggunaannya zat warna sintesis berbahaya bagi kesehatan dan lingkungan karena mengandung racun berupa logam berat, sehingga mulai dilakukan alternative penggatinya yaitu dengan cara megembangkan zat warna alami dari sumber-sumber hayati seperti buah mangrove spesies rhizopora mucronata/stylosa, kulit kayu mahoni, dan kulit kayu ting, tetapi zat warna alami ini ada kendala dalam pengaplikasiannya terutama pada batik. Untuk menanggulangi masalah tersebut diatas maka dibuat alat ekstraktor dan evaporator yang menghasilkan zat warna alami dalam bentuk konsentrat tinggi. Untuk menghasilkan konsentrat tinggi zat warna alami dari sumber hayati (mangrove spesies rhizopora mucronata/stylosa, kulit mahoni, dan kulit kayu tingi diperlukan alat ekstraktor-evaporator. Spesifikasi alat ekstraktor-evaporator terdiri atas tangki berdiameter $20 \mathrm{~cm}$ dan tinggi $40 \mathrm{~cm}$, peralatan ini diaplikasikan di mitra pertama dan pewarnaan di mitra kedua, Pada kegiatan yang dilakukan bagi mitra pertama adalah membuat zat warna alami dengan menggunakan alat ekstraktor-evaporator, sedangkan mitra kedua mengaplikasikan zat warna alami yang dihasilkan oleh mitra pertama.
\end{abstract}

Kata Kunci: batik, ekstraktor-eveporator, zat warna alami

\section{PENDAHULUAN}

Perkembangan IPTEK (Ilmu Pengetahuan dan Teknologi) semakin pesat, antara lain perkembangan pengadaan peralatan proses yang semakin canggih, dan dimanfaatkan untuk memenuhi kebutuhan manusia. Penggunaan yang lebih efektif dan efisien dapat memudahkan manusia itu sendiri dalam memperoleh hasil yang optimal.

Seiring perkembangan jaman, industri pakaian khususnya batik lebih tertarik menggunakan pewarna sintesis, karena pewarna sintesis dinilai lebih praktis dan lebih murah dibandingkan pewarna alami. Padahal pewarna alami dapat dengan mudah terdekomposisi oleh bakteri dalam tanah dan tidak mengandung senyawa berbahaya seperti logam berat.

Oleh karena itu perlu adanya aplikasi pewarna alami agar dapat mempertahankan kualitas batik dengan bahan-bahan alami.
Contohnya dengan memanfaatkan buah mangrove spesies rhizopora stylosa/mucronata, kulit kayu mahoni dan kulit kayu tingi yang mengandung pewarna alami.

Untuk memperoleh zat warna alami dari buah mangrove, mahoni dan tingi perlu dilakukan proses ekstraksi (padat-cair). Ekstraksi adalah suatu istilah yang digunakan untuk setiap kegiatan, di mana komponen-komponen pembentuk bahan berpindah ke dalam cairan lain (pelarut).

Metode paling sederhana untuk mengekstraksi padatan adalah mencampurkan seluruh bahan padat dengan pelarut, lalu memisahkan larutan dengan padatannya. Dalam proses ekstrasi ini, teknologi yang digunakan untuk menghasilkan zat warna alami adalah ekstraktor-evaporator. Rangkaian alat ekstraktor 
ini terhubung langsung dengan evaporator, sehingga akan menghasilkan ekstrak tanin pekat sebagai pewarna alami.

Penelitian tentang pembuatan zat warna alami dari kayu mahoni, tingi, dan jambal telah dilakukan menggunakan alat spray dryer dengan mengumpankan $1000 \mathrm{ml}$ ekstrak kulit kayu mahoni, kulit kayu tingi dan kulit kayu jambal. Hasil terbaik ekstrak didapat pada perbandingan 1:5 dan spray dryer suhu $85-90^{\circ} \mathrm{C}$, waktu 60 menit, untuk serbuk zat warna alami kulit kayu mahoni sebanyak 19,86 gram, serbuk zat warna alami kulit kayu tingi sebanyak 19,23 gram, dan serbuk zat warna alami kulit kayu jambal sebanyak 18,76 gram (Paryanto, dkk.,2013).

Paryanto, dkk. (2015) juga telah melakukan penelitian dengan mengambil tanin dengan cara ekstraksi kontinyu menggunakan simulasi batch 3 tahap dengan varibel suhu $60^{\circ} \mathrm{C}$, $70^{\circ} \mathrm{C}$ dan $80^{\circ} \mathrm{C}$ serta variasi kecepatan pengadukan $200 \mathrm{rpm}, 300 \mathrm{rpm}$, dan $400 \mathrm{rpm}$ selama 60 menit. Hasil yang diperoleh didapatkan kadar tanin yang terekstrak paling banyak pada suhu $80^{\circ} \mathrm{C}$ dan kecepatan pengadukan $200 \mathrm{rpm}$ selama 60 menit sebesar 1,3618\% dan juga pada kecepatan pengadukan $400 \mathrm{rpm}$ dan suhu $60^{\circ} \mathrm{C}$ selama 60 menit sebesar $1,011 \%$.

Pengambilan zat warna alami dari buah mangrove secara ekstraksi padat cair batch tiga tahap dalam skala pilot plan telah dilakukan dengan menggunakan pelarut air rasio $1 \mathrm{~kg}$ mangrove : 10 Liter air, kondisi operasi $100^{\circ} \mathrm{C}$, tekanan satu bar selama satu jam, hasil yang didapat kadar tannin sebesar 1662 ppm dengan volume ekstrak 5,23 Liter (Paryanto.dkk,2017a).

Penelitian untuk menentukan kecepatan transfer massa $(\mathrm{kc})$, diffusivitas (De) dan konstanta Henry $(\mathrm{H})$. Buah mangrove dipotong kecil-kecil dan dikeringkan kemudian diekstraksi menggunakan pelarut air dengan perbandingan massa bahan dan pelarut $1: 10$ pada suhu $100^{\circ} \mathrm{C}$ selama 60 menit, kecepatan pengadukan $500 \mathrm{rpm}$. Kondisi operasi yang optimum untuk ekstraksi tanin dari buah mangrove (Rhizophora stylosa) adalah pada kecepatan pengadukan $500 \mathrm{rpm}$, perbandingan massa bahan terhadap pelarut 1:10 menggunakan pelarut air selama 60 menit dan suhu $100^{\circ} \mathrm{C}$ ekstraksi dengan yield $0,4326 \%$. Hasil yang diperoleh adalah nilai koefisien transfer massa (kc) sebesar $1,6 \times 10^{-3} \mathrm{~cm} / \mathrm{s}$, Diffusivitas effektif (De) sebesar $6,7 \times 10^{-4} \mathrm{~cm}^{2} / \mathrm{s}$, dan konstanta
Henry $(\mathrm{H})$ bernilai $2,6 \times 10^{-2}$ dengan SSE bernilai $6,93 \times 10^{-10}$. (Paryanto.dkk,2017b).

Pengambilan tannin dilakukan menggunakan ekstraktor evaporator. Ekstraksi ini dinilai cukup praktis dikarenakan ekstraksi zat warna dilakukan terhubung dengan pendingin balik. Ekstrak yang dihasilkan berupa tanin pekat langsung dapat digunakan untuk pewarna batik.

Proses perancangan ekstraktor evaporator untuk pengambilan tanin dari buah mangrove spesies Rhizophora mucronata dimulai dengan menentukan kapasitas ekstraktor yaitu sebesar 15 L. Kemudian dilakukan perhitungan serta perancangan alat. Setelah dilakukan perancangan alat, ekstraktor dapat didesain dan dapat dilakukan uji kinerja ekstraktor-evaporator.

Tujuan dari penelitian ini adalah merancang dan membuat ekstraktor-evaporator skala pilot plan yang diaplikasikan di mitra UKM batik soul craf di desa Kuwiran, Kecamatan Banyudono, Kabupaten Boyolali.

\section{METODE PENELITIAN}

\section{a) Alat dan Bahan}

Alat yang digunakan adalah rangkaian ekstraktor-evaporator hasil rancangan untuk proses ekstraksi. Berikut ini skema rangkaian peralatannya

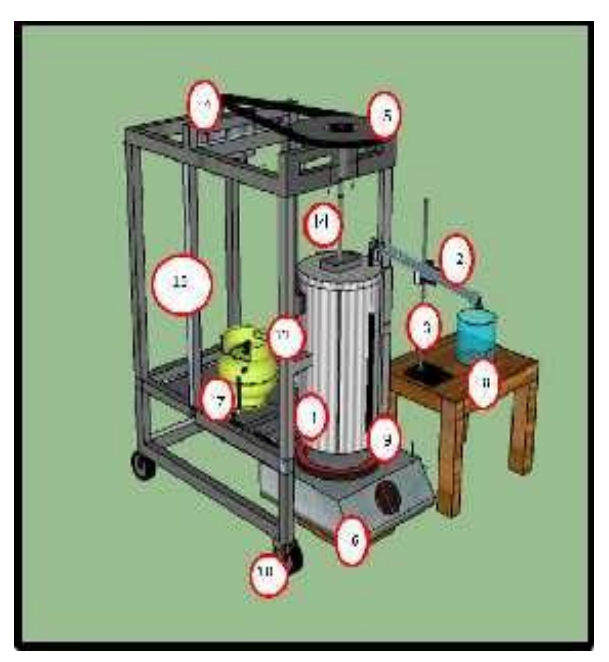




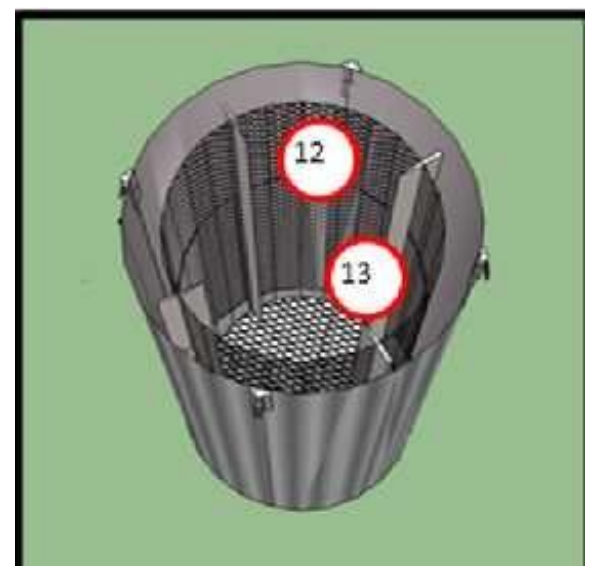
1. Tangki
9. Gelas Penduga
2. Pendingin balik
10. Roda
3. Statif
4. Motor
11. Engsel
12. Tangki Penyaring
5. Pulley
6. Kompor
13. Buffle
14. Pengaduk
7. Gas LPG
15. Support
8. Wadah

\section{Gambar 1. Ekstraktor- Evaporator}

Bahan yang diganakan adalah buah mangrove spesies Rhizopora mucronata yang berasal dari Bontang, Kalimantan Timur, kulit kayu mahoni dan kulit kayu tingi.

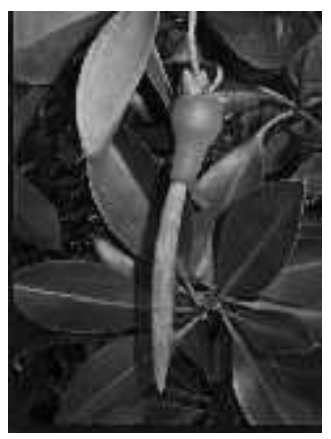

\section{Gambar 2. Buah Mangrove}

\section{b) Cara Penelitian}

Cara penelitian dimulai dengan pembuatan tangki ekstraktor. Dimana tangki tersebut berbahan stainless steel dengan ukuran 80 x $50 \mathrm{~cm}$. Bagian bawah tangki didesain dengan bentuk spherical dish bottom dengan tinggi $6 \mathrm{~cm}$. Terdapat lubang pada dasar tangki dengan diameter $2 \mathrm{~cm}$ untuk tempat menyambungkan kran keluaran hasil ekstraksi. Kemudian dilakukan pembuatan tutup tangki dengan cara memotong plat stainless steel dengan diameter $22 \mathrm{~cm}$. Bagian tutup tangki diberi lubang sebanyak 3 buah dengan diameter masing masing $2 \mathrm{~cm}$, sebagai tempat termometer, pipa keluaran uap, dan lubang masukknya pengaduk

Kemudian dilakukan pembuatan tangki penyaring dari lembaran stainless steel dengan ukuran 60 x $40 \mathrm{~cm}$. Lembaran tersebut dibentuk tabung dengan diameter $19 \mathrm{~cm}$ dan tinggi 40 $\mathrm{cm}$ hingga membentuk tangki. Lalu dilakukan pelubangan pada semua sisi tangki dengan lubang kecil $2 \mathrm{~mm}$. Baffle juga dirancang pada tangki penyaring denga ukuran masing-masing lebar $1,5 \mathrm{~cm}$ dan tinggi $40 \mathrm{~cm}$.

Pembuatan pengaduk dilakukan dengan memotong lembaran stainless steel hingga berbentuk persegi panjang dengan bentuk tipe 4 paddle. Batangan stainless steel tersebut dipotong dengan tinggi $1,5 \mathrm{~cm}$ dan panjang $2 \mathrm{~cm}$. Kemudian dilakukan pengelasan stainless steel dengan pengaduk.

Perancangan alat tersebut didesain menggunakan Autocad :

Tangki ekstraktor
Fungsi
: Proses ekstraksi
Bentuk : : Silinder vertikal
Bahan : stainless steel 304
Kapasitas $\quad: 15$ Liter

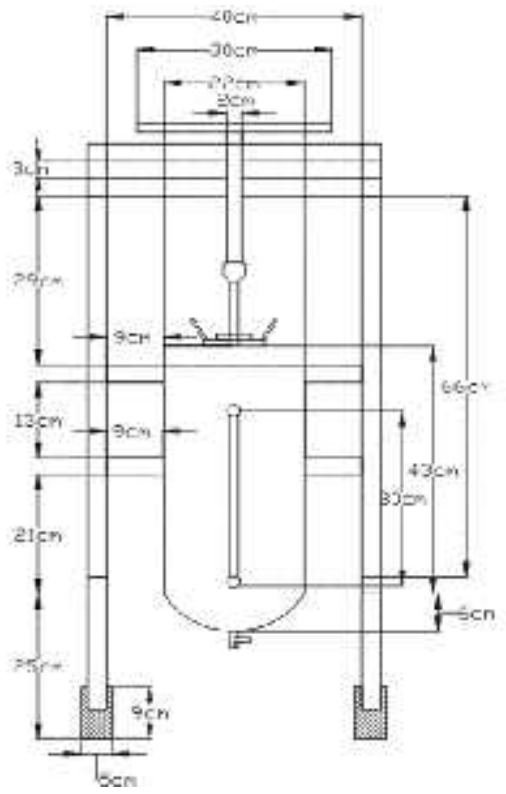

Gambar 3. Desain Ekstraktor

Tangki penyaring

Baha : Stainless steel 304

Diameter $: 19 \mathrm{~cm}$ 
Tinggi $\quad: 40 \mathrm{~cm}$
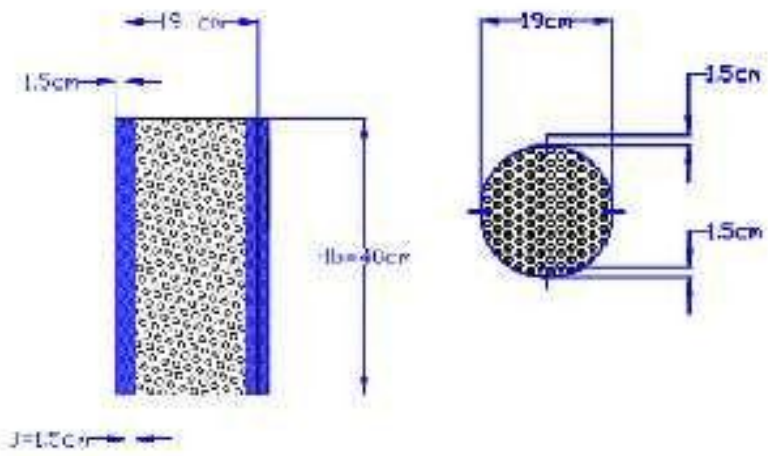

Gambar 4. Desain Tangki Penyaring

Pengaduk

\begin{tabular}{|c|c|}
\hline Bahan & : Stainless steel \\
\hline Tipe & $\begin{array}{l}\text { : Impeller paddle with } 4 \\
\text { blades }\end{array}$ \\
\hline Jumlah & : 3 buah \\
\hline
\end{tabular}

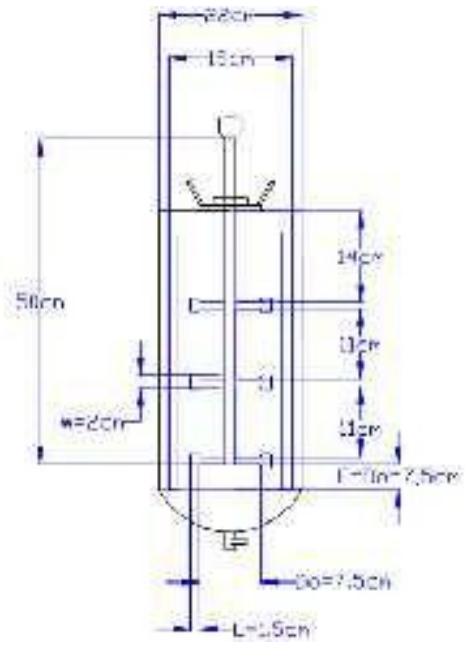

Gambar 5. Desain Pengaduk c.

\section{Cara Analisa}

Penentuan kapasitas perancangan berdasarkan perhitunagan dari studi literatur.

a.) Perancangan Tangki

Perancagan tangki berdasarkan perhitungan :

- Menentukan Volume tangki :

1. Menghitung Densitas Buah Mangrove

Densitas =

2. Menghitung volume buah mangrove
Volume = $\quad \frac{\text { massa buah mangrove }}{\text { densites buah mangrove }}$

3. Kapasitas bahan total $=$ volume pelarut +volume buah mangrove.

4. Ruang uap $=\frac{1}{3} \quad x$ volume bahan total

5. Menentukan Kapistas tangki total Kapasitas bahan total = volume ruang uap + volume pelarut + volume buah mangrove

Menentukan tinggi dan diameter tangki Perhitungan berdasarkan persamaan

Volume ekstraktor $=1 / 4 . \pi . \mathrm{D}^{2} . \mathrm{H}$

b). Menentukan tinggi minimum baffle.

Tinggi minimum baffle + tinggi bahan

Tinggi bahan $=\frac{\text { Volume bahan }}{\frac{\pi}{4} \cdot D^{2}}$

J $\quad \frac{1}{\mathrm{D}_{2}}$

c). Perancangan Pengaduk

Perancangan yang digunakan pada alat ekstraktor evaporator ini adalah tipe paddle with 4 blade. Pemilihan bersumber dari Gupta " $A$ Textbook of Machine Design”, 2002.

$$
\begin{aligned}
& \text { Do }=1 / 3 \text { Dt } \\
& \mathrm{W}=1 / 4 \text { Do } \\
& \mathrm{L}=1 / 5 \text { Do } \\
& \mathrm{E}=\text { Do d). Daya motor }
\end{aligned}
$$

Bentuk pengaduk impeller with 4 blades mirip dengan axial turbine with 4 blades jadi dalam perhitungan ini dalam

$$
\begin{aligned}
& \operatorname{Re}=\frac{\rho \cdot n \cdot D i^{2}}{\mu} \\
& \text { Po }=\text { penentuan Power Number (Po), } \\
& \text { menggunakan kurva no.19 pada gambar } \\
& 4.77 \text { dari buku "Unit Operations" (Mc } \\
& \text { Cabe,2002) }
\end{aligned}
$$

e). Menentukan Kecepatan Pengadukan, dengan penambahan pillieg butiamefer ove pada pulley motor $(\mathrm{d} 1)^{2}$ Điañnetête pulley pengaduk (d2) Kecepatan Motor 


$$
\begin{aligned}
& \text { dalam rpm (N1) Asumsi efisiensi } 70 \% \\
& =1000 \mathrm{rpm}(1 / 4 \mathrm{hp}) \\
& \quad \mathrm{N}_{1} / \mathrm{N}_{2}=\mathrm{d}_{1} / \mathrm{d}_{2}
\end{aligned}
$$

\section{HASIL DAN PEMBAHASAN}

\section{a.) Ekstraktor}

Penentuan kapasitas ekstraktor evaporator berdasarkan jumlah bahan $1 \mathrm{~kg}$ sumber hayati dan 10 liter pelarut air dengan proses batch diperoleh kapasitas ekstraktor 15 liter. Adapun dimensi ekstraktor adalah sebagai berikut :

Diameter Tangki : $22 \mathrm{~cm}$

Tinggi Tangki $: 43 \mathrm{~cm}$

Ekstraktor dilengkapi dengan pengaduk untuk membuat kontak antara bahan dan pelarut agar lebih baik dalam transfer massa. Sebagai penggerak dari pengaduk digunakan motor dengan sistem transmisi pulley. Berikut dibawah ini ekstraktor evaporator yang telah dibuat :

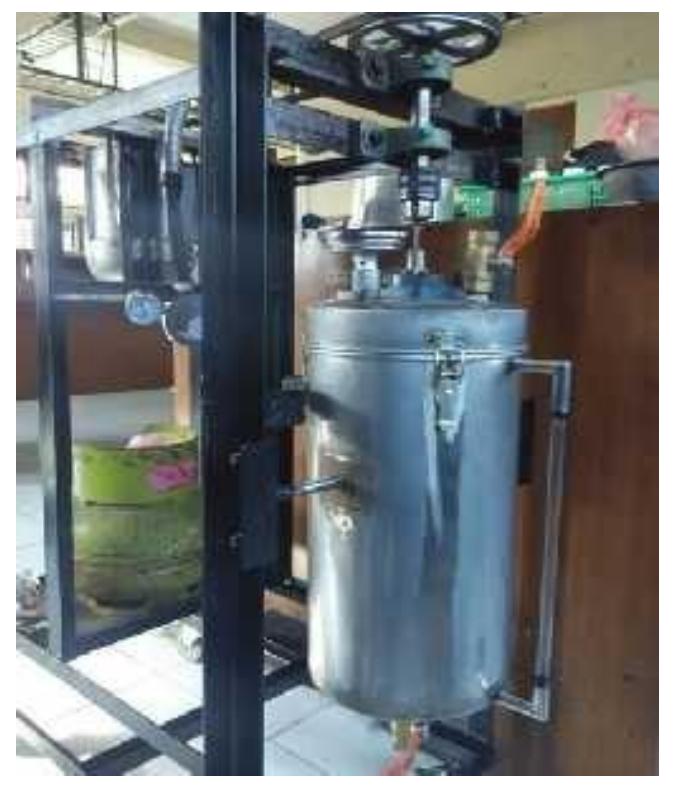

\section{Gambar 6. Ekstraktor-Evaporator}

Ekstraktor-evaporator tersebut dibuat dari bahan lembaran plat stainless steel dengan tebal $1 \mathrm{~mm}$ dalam skala pilot plant. Ekstraktorevaporator ini dilengkapi dengan pengaduk (agitator) berkecepatan $1000 \mathrm{rpm}$ dengan tipe impeller paddle with 4 blade dengan ukuran tiap paddle 1,5 $\mathrm{cm}$ x $2 \mathrm{~cm}$ yang berjumlah 3 tingkat. Jarak masing masing tingkatan $11 \mathrm{~cm}$. Pengaduk berfungsi untuk mengolak bahan sat ektraksi berlangsung sehingga ekstraksi yang terjadi diharapkan maksimal karena bidang kontak bahan dengan pelarut menjadi semakin besar. Adanya baffle dalam tangki membuat proses pengadukan diharapkan semakin baik karena tidak terjadi vorteks pada saat pengadukan berlangsung. Selain itu tangki penyaring berfungsi agar pada saat ektraksi selesai, dapat dengan mudah memisahkan ekstrak dan residu padatan. Ektraktor-evaporator dilengkapi termometer yang diletakkan pada tutup tangki. Tutup tangki harus tertutup rapat selama ekstraksi berlangsung agar tidak ada uap yang keluar, maka terdapat 3 buah pengunci antara tutup dan badan tangki ekstraktor-evaporator. Pada tutup tangki juga terdapat pipa keluaran uap yang dirangkai dengan pendingin balik, berfungsi sebagai jalur keluar uap yang akan dikondensasi.

Terdapat pengaduk pada ekstraktor evaporator yang digerakan oleh motor $1 / 4 \mathrm{HP}$ dilengkapi dengan pulley untuk mengatur kecepatan putar pengaduk. Proses Ekstraksi berlangsung dalam tangki dengan pelarut air. Ekstraksi yang terjadi adalah ekstraksi padat- cair (leaching).

\section{b) Pengujian Alat}

Proses ini berlangsung secara batch dengan cara memasukan bahan sebanyak $1 \mathrm{~kg}$ kedalam tangki ekstraktor evaporator pada bagian tangki penyaring kemudian memasukkan air ke dalam tangki ekstraktor evaporator sebanyak 10 liter atau sampai tanda batas pada gelas penduga. Pendingin balik dihubungkan kedalam rangkaian alat ekstraktor evaporator. Setelah itu motor dinyalakan dan kompor dihidupkan dengan tujuan pemanasan hingga temperatur mencapai $100^{\circ} \mathrm{C}$. Kemudian menjaga keadaan temperatur $100^{\circ} \mathrm{C}$ selama 1 jam, ketika temperatur mencapai $100^{\circ} \mathrm{C}$. Setelah 1 jam ekstraksi, dilakukan pendinginan pada ekstraktor dengan cara mematikan kompor pemanas. Ekstrak yang dihasilkan dapat diambil melalui kran pada dasar ekstraktor. 
Dari hasil pengujian alat terlihat bahwa alat tersebut bekerja sesuai yang diharapkan dan terbukti dapat meghasilkan ektrak zat warana alami. Produk berupa cairan ektrak zat warna alami yang dapat diambil melalui kran pada dasar tangki ekstraktor.

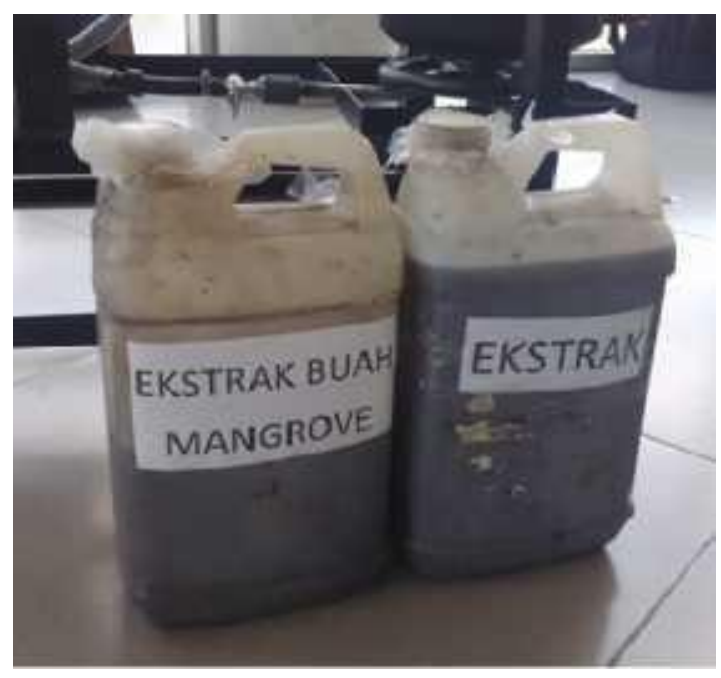

\section{c) Pembahasan}

Gambar 7. Hasil Ekstraksi

Proses ekstraksi zat warna dilakukan dengan menggunkan alat ekstraktor. Proses ini adalah ektraksi padat-cair (leaching). Bahan baku yang digunkan mengandung zat warna alami. Proses ekstraksi ini meggunakan pelarut air.

Komponen pendukung alat ekstraktor evaporator adalah gelas penduga, kompor gas, dan termometer. Gelas penduga digunakan sebagai indikator level cairan dalam tangki. Komporgas berfungsi sebagai pemanas yang diletakkan dibawah ekstraktor, sedangkan termometer untuk mengontrol suhu. Suhu yang dicapai pada proses ini adalah $100^{\circ} \mathrm{C}$ (titik didih air) karena diharapkan ekstraksi berjalan maksimal dan bertujuan untuk menguapkan air pearut sehingga konsentrasi produk ekstrak zat warna menjadi lebih pekat. Selain itu ekstraktor ini juga dilengkapi pengaduk sebagai pengolak agar seluruh permukaan bahan berkontak dengan pelarut sehingga transfer massa akan semakin besar.Dalam pembuatan ektraktor evaporator ini terbuat dari bahan stainless steel sehingga memiliki ketahanan terhadap korosi dan dapat digunakan pemanasan pada suhu tinggi (- 6,67$\left.343,33^{\circ} \mathrm{C}\right)$.

Namun masih terdapat kekurangankekurangan pada alat ini, yaitu pemanasan menggunkan kompor masih belum maksimal. Karena api yang dihasilkan dari kompor tidak terbakar sempurna sehingga tidak menghasilkan api biru dan menghasilkan bekas abu hitam pada permukaan tangki. Sehingga efisiensi energi tidak maksimal.

\section{Kesimpulan}

Ekstraktor evaporator telah berhasil dibuat untuk mengolah $1 \mathrm{~kg}$ bahan baku dan 10 Liter air secara batch.

Dimensi ekstraktor-evaporator sebagai berikut:

$\begin{array}{lll}\text { - } & \text { Diameter Tangki } & : 22 \mathrm{~cm} \\ \text { - } & \text { Tinggi Tangki } & : 43 \mathrm{~cm} \\ \text { - } & \text { Tinggi Baffle } & : 38 \mathrm{~cm} \\ \text { - } & \text { Lebar Baffle } & : 1,5 \mathrm{~cm} \\ & \text { Bahan stainless } & \end{array}$

Ekstraktor dilengkapi dengan :

- $\quad$ Pengaduk (Paddle with 4 blades)

- Gelas penduga

- $\quad$ Motor $1 / 4 \mathrm{HP}$

- $\quad$ Support yang dilengkapi roda

Ekstraktor telah diuji coba untuk mengekstraksi zat warna alami dari mangrove, mahoni dan tingi. Waktu yang digunakan untuk menghasilkan ekstrak selama 1 jam dengan suhu operasi $100^{\circ} \mathrm{C}$ dan kecepatan putar $250 \mathrm{rpm}$.

\section{Ucapan Terima Kasih}

Tim P2M mengucapkan terima kasih kepada Ristek-Dikti atas pendanaannya dengan Kontrak No.020/SP2H/PPM/DRPM/2018, LPPM UNS, UKM Batik Soul Craf, UMK Batik Cantik untuk obyek pengabdian, saudara Dewi, Ratna, Imas dan Fadila yang telah membatu dalam melaksanakan program ini.

\section{DAFTAR PUSTAKA}

Bernasconi G, 1995, “Teknologi Kimia”, Erlangga, Jakarta

Khurmi, Gupta, 2002,"A Textbook of Machine Design", Eurasia Publishing House(Pvt.) LTD, New Delhi 
Mc. Cabe Warren, C Smith Julian, Hariott Peter,"Unit Operation of Chemical Engineering",Mc Graw Hill Book

Paryanto, Puwanto A., Yunus A. 2013. Alat Pengering Kabut (Spray Dryer) untuk Pembuatan Zat Warna Alami dari Kulit Kayu Mahoni, Kulit Kayu Tingi dan Kulit Kayu Sga Jambal dalam Bentuk Konsentrat Tinggi, Seminar Nasional Rekayasa Kimia Dan Proses, UNDIP Semarang : ISSN 14114216

Paryanto, dkk. 2015. Zat Warna Alami dari Mangrove Spesies Rhizophora Mucronata sebagai Pengganti Pewarna Sintetis untuk Batik yang Ramah Lingkungan, Seminar Nasional Pengelolaan Sumber Daya Alam dan Lingkungan, Pasca Sarjana UNDIP, Semarang, ISBN : 978-602-73313-0-3

Paryanto,dkk.2017a.'Pengambilan Zat Warna Alami dari Buah mangrove Spesies Rhizopora Mucronata secara Ekstraksi Padat-Cair Batch Tiga Tahap dalam Skala Pilot Plan", Jurnal Momentum, Vol.13, No.2, pp 5-10.

Paryanto,dkk.2017b,'Difusi dan Transfer Massa pada Ekstraksi Tanin dari Buah Mangrove (Rhizopora Stylosa)", Jurnal Rekayasa Bahan Alam dan Energi Berkelanjutan", Vol.1, No.2.pp 42-48 